\section{$16^{\circ}$ ERGODESIGN USIHC CINAHPA}

$16^{\circ}$ USIHC - Congresso Internacional de Ergonomia e Usabilidade de Interfaces Humano Computador

CINAHPA | 2017 - Congresso Internacional de Ambientes Hipermídia para Aprendizagem.

\title{
CONTRIBUIÇÕES DA AVALIAÇÃO PÓS-OCUPAÇÃO EM SALAS DE AULA DE UMA ESCOLA DO CICLO BÁSICO
}

\section{POST-OCCUPATION EVALUATION CONTRIBUTIONS IN CLASSROOMS OF AN ELEMENTARY SCHOOL}

\author{
Wanência Fernandes da Silva ${ }^{1}$, Bach. \\ Iara Sousa Castro ${ }^{2}$, D.Sc. \\ (1) Universidade do Estado de Minas Gerais \\ e-mail: wanenciafernandes@yahoo.com.br \\ (2) Universidade do Estado de Minas Gerais \\ e-mail: iarascastro@yahoo.com.br
}

Palavras-chave: Avaliação Pós-Ocupação; Ambiente Escolar; Desempenho, Comportamento. O objetivo do artigo é avaliar a o desempenho de salas de aula de uma edificação escolar. Trata-se de uma pesquisa, do tipo estudo de caso, baseada em métodos da Avaliação Pós-Ocupação. Os resultados revelam que a qualidade do ambiente construído influência no comportamento de crianças entre 3 e 5 anos.

Key-words: Post-Occupation Evaluation; School Environment; Performance, Behavior. The objetive of this article is evaluate the classroom performance in a school building. It is a real case reasearch, based on Post-Occupation Evaluation methodology. The results reveal that the quality of building facilities influence the child behavior between 3 and 5 years old. 


\section{$16^{\circ}$ \\ ERGODESIGN USIHC CINAHPA}

$16^{\circ}$ Ergodesign- Congresso Internacional de Ergonomia e Usabilidade de Interfaces Humano Tecnológica: Produto, Informações Ambientes Construídos e Transporte

$16^{\circ}$ USIHC - Congresso Internacional de Ergonomia e Usabilidade de Interfaces Humano Computador

CINAHPA | 2017 - Congresso Internacional de Ambientes Hipermídia para Aprendizagem.

\section{Introdução}

Os designers buscam proporcionar um ambiente com condições favoráveis à interação da criança com o dentro do ambiente escolar. "A configuração física do ambiente escolar e a adaptação do estudante a este meio exercem grande predominância na evolução do aprendizado" (BERNARDI e KOWALTOWSKI, 2001, p.1). Este artigo aborda uma Avaliação Pós-Ocupação - APO (PREISER, RABINOWITZ e WHITE, 1988), na sua forma clássica, realizada em um centro de educação infantil e tem como objetivo avaliar o desempenho de salas de aula de uma edificação escolar.

Com a proposta de avaliar as diferentes vertentes que compõem as transformações de uma edificação, a APO amplia horizontes e estende seus pilares, estabelecendo-se em prática e pesquisa acadêmica, a partir de uma visão mais abrangente e participativa que avalia o desempenho do Ambiente Construído. Conforme Ornstein (1992), esta metodologia pretende diagnosticar aspectos positivos e negativos e os recursos disponíveis a partir da avaliação de fatores técnicos, funcionais, estéticos e comportamentais do ambiente em uso.

\section{Metodologia}

O desenvolvimento do estudo de caso teve a duração de um ano. Para a avaliação técnica do desempenho da sala de aula, a coleta de dados baseou-se em experiências de pesquisadores envolvidos com a avaliação do desempenho do ambiente construído no Brasil, como Ornstein (1992; 1995), Azevedo, Rheinghantz e Tangari (2011) entre outros que disseminam a pesquisa e a prática da APO em edificações escolares. Para o presente artigo foram utilizados o passeio walkthrough, o mapa mental e as entrevistas devido à relevância dos dados coletados e pelo caráter qualitativo da pesquisa. Os esforços da análise de desempenho do ambiente construído foram dados nos ambientes das salas de aula ocupadas por crianças de três a cinco anos de idade. A escolha desses ambientes foi feita devido ao tempo significativo de permanência das crianças nesses espaços e porque existia uma demanda real de que, possivelmente, seria realizada uma reforma das mesmas. Foram analisados fatores técnicoconstrutivos, fatores funcionais e fatores comportamentais.

\subsection{Etapas da pesquisa}

A pesquisa foi organizada em três etapas: planejamento, condução e aplicação. Segundo Issa, Poltronieri e Ornstein $(2008$, p.4) "as etapas iniciais da APO visam dar subsídios para a compreensão da atual situação física do edifício". No sentido de familiarizar com a realidade escolar, foram realizadas coletas de informações junto à direção da escola sobre o perfil dos usuários e do quadro de funcionários, sobre o funcionamento da escola e sobre o projeto arquitetônico do local.

Na etapa do planejamento, foi necessário pedir permissão à escola, aos atores envolvidos (direção, professores e funcionários) e aos pais das crianças. Também foi importante explicar como pretendia-se conduzir a pesquisa, negociando prazos e acessos às informações necessárias. Foi negociado também quais seriam os grupos de usuários que seriam abordados, assim como e quando seriam abordados. Esses usuários forma informados e conscientizados sobre os possíveis ganhos que a pesquisa poderia lhes trazer.

Na etapa da condução, foram realizadas a coleta e a análise dos dados coletados.

Foi realizada uma pesquisa bibliográfica sobre o tema proposto para fundamentar o desenvolvimento do estudo de caso. Além de uma análise documental que consistiu em coletar documentos pertinentes à compreensão do ambiente construído, da proposta pedagógica e dos usuários da escola.

A compreensão do contexto da escola favoreceu a construção dos instrumentos, para obtenção de dados dos usuários e do quadro de funcionários da escola, assim como do projeto arquitetônico do local.Os instrumentos utilizados foram o passeio 


\section{$16^{\circ}$}

ERGODESIGN

USIHC

CINAHPA $16^{\circ}$ Ergodesign- Congresso Internacional de Ergonomia e Usabilidade de Interfaces Humano Tecnológica: Produto, Informações Ambientes Construídos e Transporte

$16^{\circ}$ USIHC - Congresso Internacional de Ergonomia e Usabilidade de Interfaces Humano Computador

CINAHPA | 2017 - Congresso Internacional de Ambientes Hipermídia para Aprendizagem. walkthrough, o mapa mental e a entrevista, que serão explicados nas subseções seguintes.

Na etapa da aplicação, os dados obtidos junto aos usuários, por meio da aplicação dos instrumentos, foram avaliados e confrontados. A partir das descobertas, foram esboçadas as recomendações e as conclusões.

\subsection{Passeio walkthrough}

A coleta de dados com os usuários foi iniciada com o passeio walkthrough, instrumento típico da APO que, normalmente, é utilizado antes dos demais instrumentos, pois ajuda a evidenciar informações que servem de base para construí-los. Antes de realizar os passeios, foram feitas visitas técnicas, para definir o trajeto e elaborar uma ficha de registro das informações que seriam coletadas. O percurso definido consistiu em percorrer os ambientes das salas de aula 1, 2 e 3 (ocupadas por crianças de 3, 4 e 5 anos), respectivamente, como mostra a figura 2 .
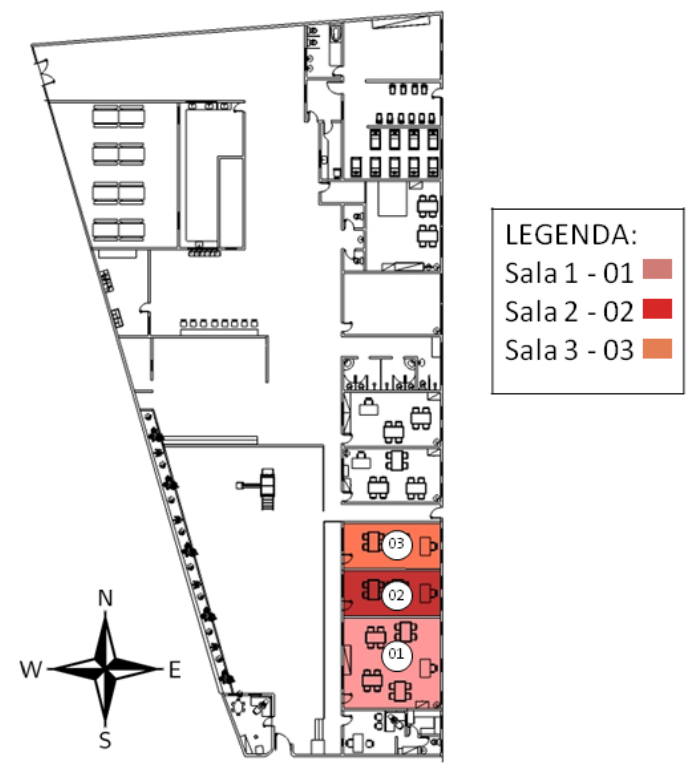

Figura 1 - Planta de localização das salas de aula

Em todos os percursos participaram um total de três professoras e vinte e um alunos, sendo 1 professora e 7 alunos por percurso. Cada passeio teve a duração média de trinta minutos e todos ocorreram no mesmo dia, no período da tarde.

\subsection{Mapa mental}

O mapa mental também "tem como objetivo identificar as percepções infantis através de uma representação gráfica para que, através desta, pudéssemos reconhecer as percepções do espaço escolar" (OLIVEIRA, 2014, p. 13).

O mapa mental foi aplicado com vinte crianças e a duas educadoras do centro infantil. Segundo Azevedo (2002, p.16), “o tempo de resposta não deve ultrapassar vinte minutos e todo o material que será utilizado no preenchimento deve ser fornecido pelo pesquisador". Partindo da premissa de que os usuários principais são crianças pequenas, optou-se por aplicar o mapa mental utilizando desenhos, pois a expressão gráfica é mais usual entre as atividades infantis nesta faixa etária.

A Ficha de registro do mapa mental (FIG. 3) foi inspirada em modelos propostos por Souza (2003) e por Azevedo (2002). Portanto, ela é constituída de campos para preenchimento do nome e da idade do participante, da data e do horário da participação e de um espaço para ser feito o desenho a partir da frase "Esta é a minha escola...".

\subsection{Entrevista}

As entrevistas segundo Ornstein (1995, p.63) é um método de grande aceitação porque se ajusta a vários tipos de pesquisa, podendo ser aplicado em diferentes tipos de ambientes, diferentes unidades físico-geográficas e ainda pode ser aplicado em uma amostra representativa, generalizando para o universo populacional em questão. Foi elaborado um roteiro para entrevistas no qual foram tratadas questões com respostas abertas, devido a maior flexibilidade para obtenção das informações. As entrevistas foram do tipo informais e semiestruturadas. Elas foram realizadas com: (a) a diretora da instituição que trabalha com crianças há trinta anos; (b) as professoras que trabalham com as crianças na faixa etária de 3,4 e 5 anos porque conhecem as crianças, as qualidades e carências das salas de aula; (c) as crianças. Estas normalmente não 
são inseridas no processo projetual e possuem experiências que podem ser aproveitadas no projeto. Assim, foram elaborados três modelos de entrevistas, um para cada tipo de respondente.

\section{Estudo de caso}

O estudo de caso foi realizado em um Centro Infantil de Belo Horizonte. Este ocupa um terreno com área de aproximadamente $2.200 \mathrm{~m}^{2}$, sendo $1.022 \mathrm{~m}^{2}$ de área construída. Ele tem a finalidade de atender as crianças do bairro e adjacências em horário integral e parcial, oferecendo as principais refeições. A eificação possui dois pavimentos distribuídos em três blocos. O grupo de usuários das salas de aula é constituído, na sua totalidade, por 91 crianças, 13 educadoras efetivas e 3 educadoras eventuais para trabalhar em todas as turmas como apoio, no período da manhã e da tarde.

\subsection{Ambiente construído das salas de aula}

Segundo Bórmio (2007, p.46) "a sala de aula apresenta um papel de destaque dentre todos os ambientes de uma escola, porque é neste ambiente que o aluno permanece a maior parte do seu tempo". Baptista (2009, p. 50) destaca a "influência que o ambiente escolar provoca no usuário podendo afetar a qualidade do ensino e da aprendizagem, além da qualidade de vida social dos alunos. Isso porque a qualidade da educação está diretamente afetada pelos atributos físicos da escola". Paes e Bastos (2013, p. 132) ressaltam a importância do ambiente corresponder às necessidades dos usuários, permitindo a fruição de seus espaços.

Entende-se que o ambiente de acordo com a sua organização, provoca determinadas percepções nos indivíduos que o ocupa, assim como influencia, condiciona e determina o grau de conforto e satisfação do usuário e seu comportamento. Para o desenvolvimento deste trabalho, foram analisadas três salas de aula, denominadas 1, 2 e 3 (FIG. 2), referentes às salas de aula do maternal III e infantil I e II.

\section{Análise do Passeio Walkthrough}

As informações coletadas nos passeios evidenciaram atributos que foram organizados nas categorias de fatores técnicos, funcionais, comportamentais.

O fator técnico constituiu-se de atributos relativos a revestimentos, manutenção, acessibilidade, circulação, iluminação natural/ artificial, acústica e conforto ambiental.

Em relação ao fator funcional foram evidenciados atributos de segurança, organização espacial, flexibilidade de uso e de layout.

O fator comportamental resumiu-se aos atributos relativos ao uso do espaço, familiaridade e a duração de permanência no espaço para realizar as atividades.

É importante ressaltar que as três salas possuem características similares e que a descrição a seguir contempla informações comuns aos três ambientes.

\subsection{Fatores técnicos}

a) Pisos - antiderrapante e em bom estado de conservação;

b) Paredes - possuem acabamento em pintura na cor branca também em bom estado de conservação;

c) Tetos - eles recebem forros de PVC branco em bom estado de conservação;

d) Esquadrias - elas são de ferro, do tipo basculante. Apesar de estarem em bom estado de conservação e de favorecer a ventilação cruzada (janelas em lados opostos nas salas de aula), suas dimensões são insuficientes para entrada de luz natural no ambiente.

e) Iluminação natural / artificial e insolação - a partir das entrevistas com os usuários foi possível detectar os principais problemas relativos à iluminação natural e artificial dos ambientes das salas de aula. A maioria dos entrevistados relatou 


\section{$16^{\circ}$}

ERGODESIGN USIHC CINAHPA $16^{\circ}$ Ergodesign- Congresso Internacional de Ergonomia e Usabilidade de Interfaces Humano Tecnológica: Produto, Informações Ambientes Construídos e Transporte

$16^{\circ}$ USIHC - Congresso Internacional de Ergonomia e Usabilidade de Interfaces Humano Computador

CINAHPA | 2017 - Congresso Internacional de Ambientes Hipermídia para Aprendizagem. que ambas não atendem bem as atividades realizadas na sala de aula Em decorrência da construção de um salão de festas no anexo ao Centro infantil, que também comprometeu o fluxo dos ventos.

f) Áreas específicas - Salas de aula: as professoras apontaram a necessidade de uma mesa com gavetas nas salas de aula, além de mais cores no ambiente. As crianças mencionam a necessidade de ter mais brinquedos.

g) Segurança - a única ressalva estaria relacionada, segundo os funcionários, aos mobiliários que são pouco ergonômicos.

h) Acústica - não foram observados problemas com a acústica no interior das salas de aula. O único barulho observado é o que as crianças produzem.

i) Conforto ambiental - em relação à circulação de ar, o tipo de esquadria e a dimensão do vão de abertura comprometem a circulação do ar no ambiente, além da construção do salão de festas em anexo, como mencionado anteriormente, dificulta ainda mais a passagem do ar, sendo necessário o uso de ventiladores para amenizar o calor.

j) Acessibilidade e circulação - existe a necessidade de se implantar mais rampas de acesso para atender alunos com necessidades especiais.

\subsection{Fatores funcionais}

a) Organização espacial - é considerada adequada pelas professoras.

b) Flexibilidade de uso e de leiaute - as salas permitem a flexibilidade de uso, mas segundo as professoras, não há mobiliários específicos para as educadoras. Os brinquedos ficam expostos em prateleiras ao alcance das crianças. Elas manifestam sentir faltam cores, enfeites e brinquedos na sala de aula. O leiaute é neutro, as cores são opacas, não servindo de estimulo às crianças.

\subsection{Fatores comportamentais}

a) Uso dos ambientes - as crianças desenvolvem as atividades propostas pela professora e brincam sob a supervisão da mesma.

b) Familiaridade - as proporções dos móveis adequadas à estatura das crianças fazem com que elas se apropriem do espaço, tendo acesso inclusive aos trabalhos elaborados por elas, que são fixados nos painéis localizados nas salas de aula.

Nas visitas realizadas, observou-se o pouco número de atividades e brincadeiras, que não se aplicam ao interacionismo, sem estímulo ao desenvolvimento e interação infantil.

c) Duração - Algumas crianças ficam na escola em período integral, a outra parcela frequenta a escola meio período.

\section{Análise do Mapa Mental}

Os resultados da aplicação do mapa mental manifestaram diversos elementos que foram categorizados de acordo com a representação. Foram identificadas categorias relativas a: ambiente físico, figuras humanas, elementos lúdicos e elementos da natureza (animais e plantas). $\mathrm{O}$ gráfico 1 indica em porcentagem a relação intensidade de representação entre essas categorias.

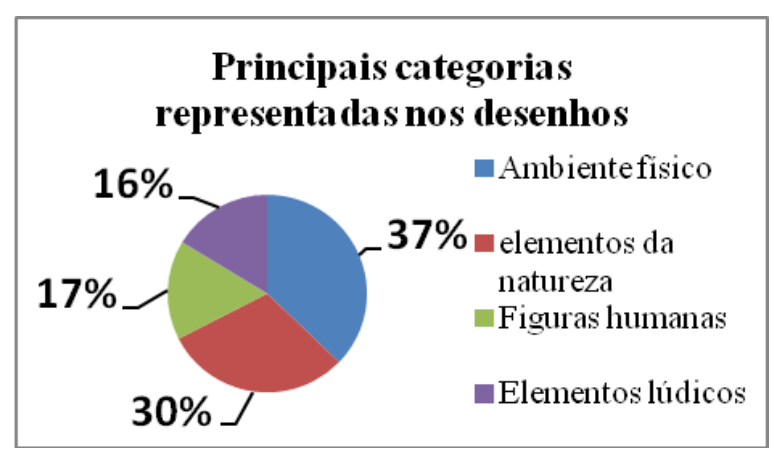

Gráfico 1 - Principais categorias representadas nos desenhos

A maioria (75\%) das crianças desenhou o ambiente físico. Tal fato demonstra a importância deste 


\section{$16^{\circ}$ \\ ERGODESIGN USIHC CINAHPA}

$16^{\circ}$ Ergodesign- Congresso Internacional de Ergonomia e Usabilidade de Interfaces Humano Tecnológica: Produto, Informações Ambientes Construídos e Transporte

$16^{\circ}$ USIHC - Congresso Internacional de Ergonomia e Usabilidade de Interfaces Humano Computador

CINAHPA | 2017 - Congresso Internacional de Ambientes Hipermídia para Aprendizagem. ambiente na concepção das crianças. Da mesma forma, observou-se uma grande incidência de elementos da natureza (45\%) que na maior parte das vezes está relacionado à ideia de ambientes ao ar livre (FIG. 4) e, também, ao parquinho (FIGs. 3 e 5).

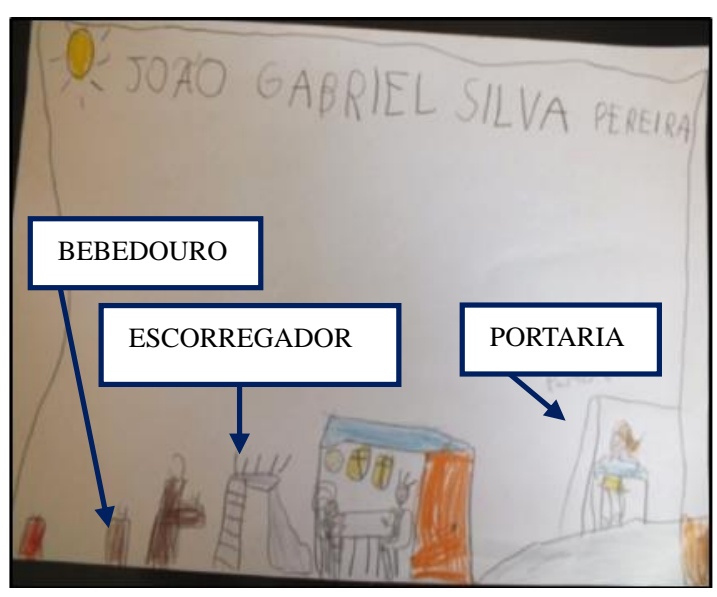

CRIANÇAS DE 5 ANOS

Figura 2 - Desenho que mostra a escola e seus elementos construtivos

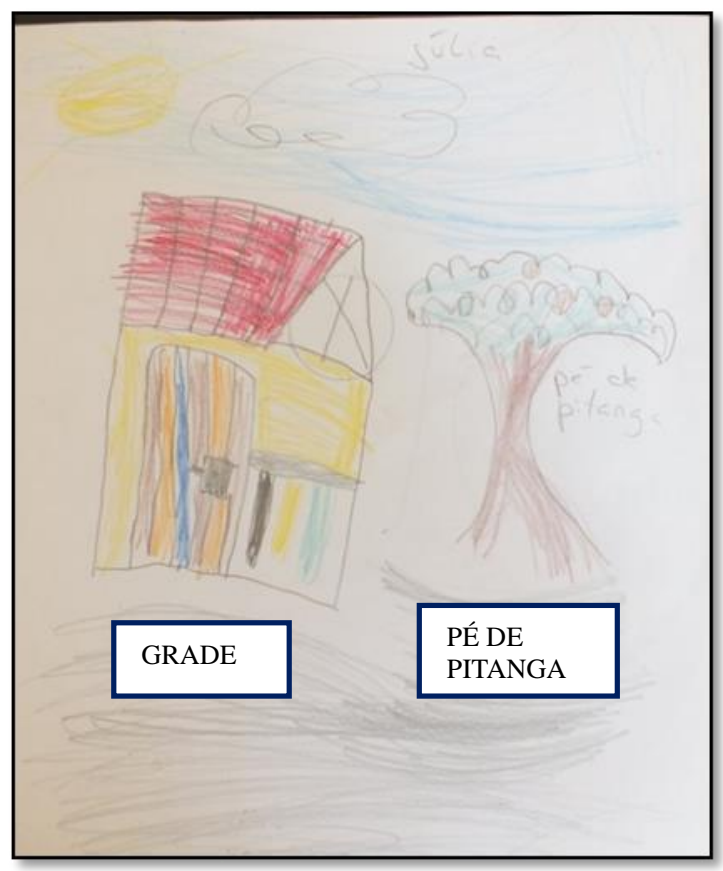

CRIANÇA DE 5 ANOS

Figura 3 - Desenho que mostra elementos da natureza e a escola
Observou-se que dentro da categoria ambiente físico, o edifício é representado significativamente pela maioria, seguido de perto pelos elementos construtivos do edifício (cores, portas, janelas, bebedouros), além dos elementos do jardim da escola com evidência para o pé de pitanga existente no local e retratado cinco vezes. Já a portaria da escola foi representada quatro vezes. Daí a grande importância da escola como referência, reconhecimento e sentido de orientação e segurança. Os elementos construtivos do Centro Infantil foram os mais desenhados pelas crianças, mostrando a importância e a familiaridade desses elementos como referência para as crianças. Pode-se observar o desenho abaixo (FIG. 4), no qual a criança representou uma chaminé na sala de aula.

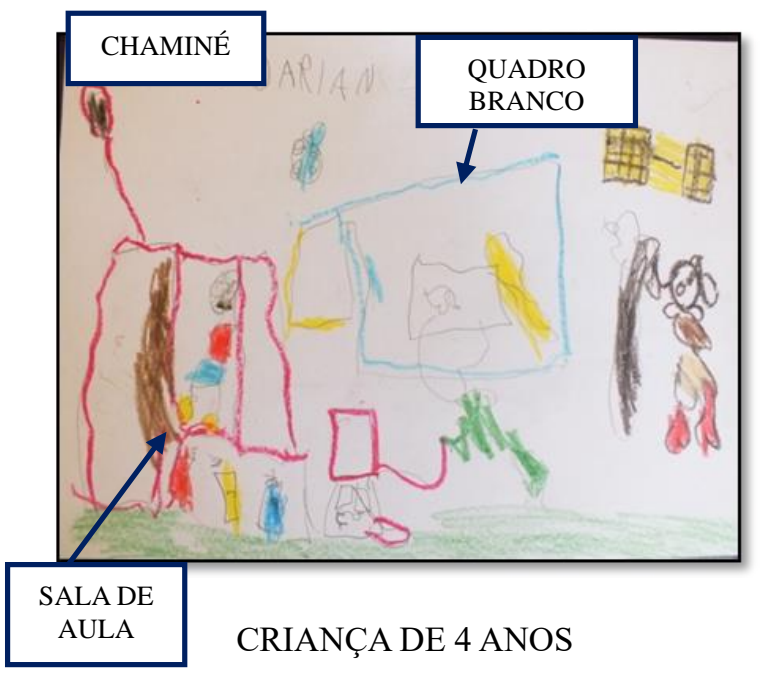

Figura 4-Desenho que mostra o parquinho, elementos construtivos e a sala de aula

$\mathrm{Na}$ categoria figuras humanas prevaleceram às imagens de colegas e das professoras nos desenhos, mostrando a importância da escola e da família para as crianças.

"Essa sou eu, meus colegas e a minha professora indo para a sala de aula." (Criança)

"Essa sou eu, meus colegas e a minha professora indo para a sala de aula." (Criança) 
$16^{\circ}$ Ergodesign - Congresso Internacional de Ergonomia e Usabilidade de Interfaces Humano Tecnológica: Produto, Informações Ambientes Construídos e Transporte

$16^{\circ}$ USIHC - Congresso Internacional de Ergonomia e Usabilidade de Interfaces Humano Computador

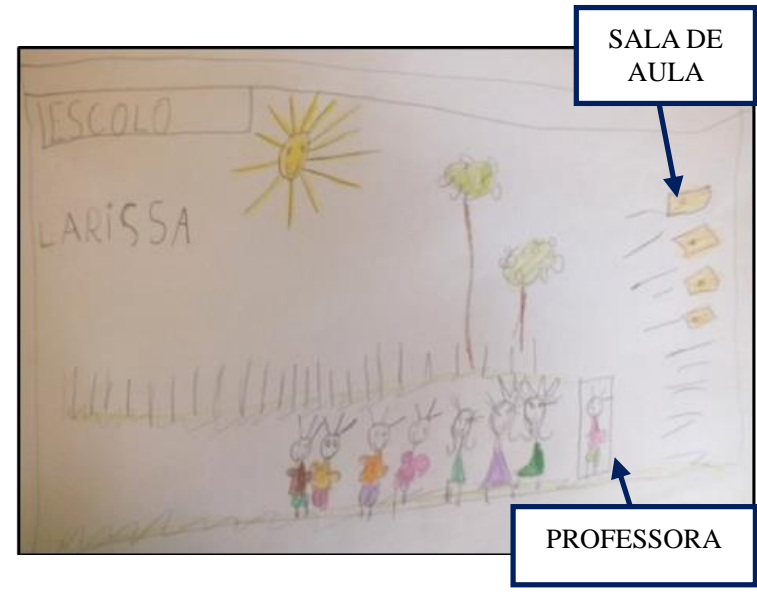

Figura 51 - Desenhos que mostram a importância da escola e da família para a criança

$\mathrm{Na}$ análise do mapa mental aplicado às professoras percebemos um grande nível de satisfação com o ambiente de trabalho, refletindo no trabalho que é desenvolvido com as crianças do Centro Infantil. Pode-se perceber nos desenhos das próprias crianças, representados acima. Quando foi percebida alguma dificuldade por parte das professoras em desenhar, explicou-se que também poderiam se expressar por escrito (FIG. 6).

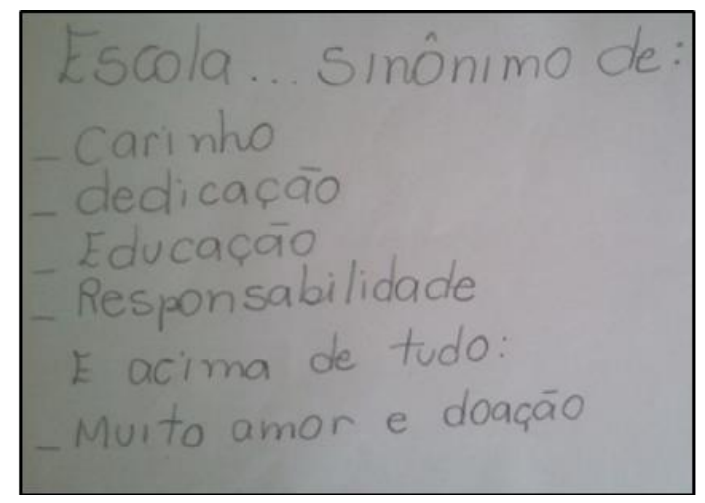

Figura 6 - Mapa Mental aplicado à professora do maternal

\section{Análise de entrevistas}

As entrevistas com diferentes tipos de usuários possibilitaram comparar as diferentes percepções dos usuários sobre o ambiente. Os resultados revelaram o seguinte:
A direção da escola percebe que o sol que incide todo o período da tarde sob os pátios da escola, dificultando o trabalho nas áreas externas. Também atentou para a relação entre as características do ambiente com a segurança, quando mencionou ter ocorrido, recentemente, a queda de uma criança em um brinquedo no pátio.

As professoras relataram que o desconforto no ambiente da sala de aula pelas crianças é expresso pela irritação e pelo cansaço.

"Elas ficam muito agitadas e cansadas". (Professora)

"As crianças ficam indispostas e agitadas". (Professora)

"Toda hora pedem para beber água".

(Professora)

Em se tratando de mudanças no ambiente, segundo as professoras "algumas crianças não querem ceder o lugar". Além das atividades desenvolvidas em sala de aula, são desenvolvidas também atividade extraclasse no pátio coberto ou na sala de TV. As professoras consideram importante as crianças estarem bem ambientadas e que a "utilização do lúdico no aprendizado é fundamental". Ressaltaram também que a disposição do mobiliário deveria ser modificada e que as janelas deveriam ser substituídas por outras maiores. Em relação à iluminação artificial das salas, a maioria relatou a necessidade aumentar a intensidade luminosa nos ambientes das salas de aula 1, 2 e 3. Em relação ao mobiliário, concordam sobre a sua adequação com a estatura das crianças, porém sugeriram a escola adquirir mais armários.

A maioria das crianças relatou que o local da escola que mais gostam é a área do escorrega (pátios parcialmente coberto) e, na sequência, a sala de TV. Porém segundo elas, a escola "poderia ter mais brinquedos". Os meninos relatam a vontade de que a escola ofereça uma quadra de futebol. Em geral, os relatos das crianças sugerem a necessidade de se incorporar o lúdico no seu cotidiano, enfatizando a importância do brincar e interagir. 


\section{Recomendações}

Após a análise dos dados coletados durante o estudo realizado no Centro Infantil, com a aplicação dos instrumentos da APO já mencionados, foi possível identificar alguns problemas e gerar algumas recomendações de melhorias para uma possível intervenção no local. Estas recomendações foram classificadas em: curto e médio prazo, porque a escola já estava passando por reformas no período em que foi realizada a pesquisa, possibilitando alguma intervenção.

\section{A curto prazo, recomenda-se:}

Em relação ao conforto lumínico (baixo nível de iluminamento nas salas de aula), percebeu-se a necessidade de aumentar o nível do mesmo no local. É sugerido aumentar a proporção das aberturas nas esquadrias das salas de aula.

Em se tratando do conforto térmico (pouca ventilação), recomenda-se inserir maior quantidade de vegetação arbórea próxima às salas de aula. Isso favoreceria também diversificar espécies, assim como ampliar a área verde da escola.

Para melhorar as condições de segurança, sugere-se adequar a altura do peitoril das janelas à estatura das crianças, e colocar grades nas janelas para evitar a queda das crianças.

A médio prazo, recomenda-se:

No caso da ambientação interna, o layout está confuso. Foi observada que as salas de aula são pouco atrativas. Sugere-se a adotar um mobiliário mais confortável, nas salas de aula 1, 2 e 3 para melhorar o desenvolvimento das atividades. Essa ambientação interna das salas de aula deve incorporar um estudo do uso de mais cores e formas na comunicação visual interna das mesmas, enfatizando o caráter lúdico nestes ambientes.

Para o parquinho, sugere-se a compra de novos brinquedos.
Com base na experiência deste Estudo de Caso desenvolvido em um Centro de Educação Infantil, relaciona-se, a seguir, considerações relevantes para projetos futuros de mesma natureza: desenvolver a APO, sempre que possível, com uma equipe multidisciplinar (arquitetos, psicólogos, educadores, pedagogos e outros); estabelecer parâmetros projetuais relativos a organização espacial, circulações, dimensionar o espaço e o mobiliário de acordo com as características antropométricas da criança; integrar os ambientes externos aos internos, visualmente, por meio de aberturas adequadas e peitoril das janelas na altura das crianças; proporcionar mobiliário ergonomicamente adequado para os adultos.

Além disso, é importante para o desenvolvimento infantil permitir uma real apropriação do ambiente por parte da criança, criando ligações de afeto, reconhecimento e valorização, assim como o incentivo a atividade lúdica e a experimentação.

Procurar verificar, junto à equipe multidisciplinar, as possíveis formas de interferência dos espaços sem deixar de priorizar o enfoque no usuário principal da edificação.

\section{Conclusões}

A aplicação dos instrumentos para Avaliação PósOcupação no espaço construído das salas de aula foi fundamental para o entendimento das necessidades e desejos dos usuários, assim como, para a formulação de diretrizes para uma possível intervenção.

Os designers podem interagir com os usuários do espaço na busca de soluções consensuais, procurando conhecer as atividades desenvolvidas nos espaços para os quais estão projetando e, principalmente, as características das crianças para as quais estão projetando.

As interpretações espaciais concebidas pelos designers podem ser reconstruídas em coerência com as atividades desenvolvidas no local e a partir do conhecimento das necessidades dos usuários, 
considerando valores e expectativas daqueles que vivenciam o espaço.

Fazer projetos adequados não é uma tarefa fácil, entretanto cabe aos profissionais, arquitetos e designers, buscarem em seus conhecimentos, alternativas que viabilizem os projetos, de maneira que esses atendam ao máximo as necessidades e expectativas dos usuários.

\section{Referências}

AZEVEDO, G. A.; RHEINGANTZ, P. A.; TÂNGARI, V. R. O Lugar do Pátio Escolar no Sistema de Espaços Livres: uso, forma e apropriação. Rio de Janeiro: Proarq/FAU/UFRJ, 2011. v. 1. 203p. Disponível em: <

https://silviomacedo.files.wordpress.com/2011/11/ar tigo-22.pdf>. Acesso em: 8 ago. 2015

\section{AZEVEDO, G. A. Arquitetura Escolar e}

Educação: Um Modelo Conceitual de Abordagem Interacionista. 2002, 236f. Tese (Doutorado em Engenharia de Produção). Programa de Pós Graduação de Engenharia da Universidade Federal do Rio de Janeiro, Rio de Janeiro. Disponível em: $<$ http://www.fau.ufrj.br/prolugar/assets/g_arteiro.pdf >. Acesso em: 02 Out. 2016.

BAPTISTA, C. A. A. Metodologia para avaliação Pós-Ocupação em centros municipais de educação infantil de Vitória. 2009. $212 \mathrm{f}$. Dissertação (Mestrado em Engenharia Civil). Universidade Federal do Espírito Santo, Vitória. Disponível em:

<http://portais4.ufes.br/posgrad/teses/nometese_251 _Cristianne\%20Asis\%20de\%20Abreu\%20Baptista. pdf> Acesso em: 29 Set. 2016.

BERNARDI, N.; KOWALTOWSKI, D. C. Avaliação da Interferência Comportamental do Usuário para a melhoria do Conforto Ambiental em espaços escolares: Estudo de caso em Campinas SP. In: Anais... ENCAC VI / ELACAC II Encontro Nacional e Latino-Americano de conforto no ambiente construído, 2001. São Pedro: ANTAC, 2001.p.8. Disponível em: <http://www.dkowaltowski.net/1061.pdf>. Acesso em: 29 Set. 2016.

BORMIO, M. F. Avaliação Pós-Ocupação ambiental de escolas da cidade de Bauru (SP) e Lençóis Paulista: um estudo ergonômico visto pela metodologia EWA. 2007. 163f. Dissertação ( Mestrado em Desenho Industrial). Universidade Estadual Paulista, Faculdade de Arquitetura, Artes e Comunicação, Bauru. São Paulo. Disponível em: $<$ http://www.faac.unesp.br/Home/PosGraduacao/De sign/Dissertacoes/mariana_bormio.pdf $>$. Acesso em: 18 abr. 2016.

CASTRO, I. S. A capitalização da experiência do uso do ambiente construído: contribuições da Avaliação Pós-Ocupação e da Análise Ergonômica do Trabalho. Estudo de caso realizado em um hospital-dia VIH. 2010. 376 f. Tese (Doutorado em Arquitetura). Rio de Janeiro: Escola de Arquitetura da Universidade Federal do Rio de Janeiro.

Disponível em:

<http://www.fau.ufrj.br/prolugar/arq_pdf/teses/teseIaraCASTRO.pdf.> Acesso em: 02 Out. 2016.

ISSA, Maíra Piccolotto; POLTRONIERI, Julyane Pereira; ORNSTEIN, Sheila Walbe. Procedimentos para Avaliação Pós Ocupação (APO) de Edifícios Escolares: O caso da E. E. Fernando Gasparin, na cidade de São Paulo. In: Anais... NUTAU'2008 Espaço sustentável: inovações em edifícios e cidades. São Paulo: USP, 2008. 9p. Disponível em: <http://www.usp.br/nutau/CD/82.pdf >. Acesso em: 02 Out. 2016.

OLIVEIRA, A. A. Taciana. A relação psicossocial entre 0 ambiente e a aprendizagem: crianças de 7 a 10 anos e seu ambiente escolar. 2014, 111p. Trabalho de graduação. Universidade do Estado de Minas Gerais. Escola de Design. Belo Horizonte. Disponível em:

<file:///C:/Users/Wanessa/Downloads/TCC\%20\%20 Taciana\%20Albertina\%20Amorim\%20de\%20Olivei ra\%20(1).pdf>. Acesso em: 02 Out. 2016.

ORNSTEIN, S. W.; ROMÉRO, M. (Col.). Avaliação Pós-ocupação (APO) do Ambiente Construído. São Paulo: Studio Nobel, 1992. 


\section{ORNSTEIN, S. Ambiente construído e}

comportamento: a avaliação pós-ocupação e a

qualidade ambiental. São Paulo: Studio Nobel, 1995.

PAES, F. S. R.; BASTOS, E. G. L. Qualidade ambiental na edificação: o caso das escolas públicas da cidade do Rio de Janeiro. In: Anais...

ENCAC/ELAAC XII Encontro Nacional e VIII Latino americano de Conforto no Ambiente Construído, 2013, 10p. Disponível em:

<http://periodicos.unb.br/index.php/paranoa/article/ viewFile/12302/8588> Acesso em 30 Set. 2016.

PREISER, W.; RABINOWITZ, H.; WHITE, E. Post-Occupancy Evaluation. New York:Van Nostrand Reinhold, 1988.

RHEINGANTZ, P. A.; AZEVEDO, G. A.; BRASILEIRO, A.; ALCANTARA, D.; QUEIROZ, $M$. Observando a qualidade do lugar:

Procedimentos para avaliação Pós-Ocupação. Rio de Janeiro: Universidade Federal do Rio de Janeiro, 2009, 117p. Disponível em:

<http://www.fau.ufrj.br/prolugar/arq_pdf/livros/obs _a_qua_lugar.pdf $>$. Acesso em: 02 Out. 2016.

\section{SOUZA, F. S. A qualidade do espaço construído} da creche e suas influências no comportamento e desenvolvimento da autonomia em crianças entre 2-6 anos. Estudo de caso: Creche UFF. 2003.

166f. Dissertação (Mestrado em Arquitetura). Universidade Federal do Rio de Janeiro. Faculdade de Arquitetura e Urbanismo. Programa de Pós Graduação em Arquitetura, Rio de Janeiro. Disponível em:

<http://www.fau.ufrj.br/prolugar/dissert_f_souza.ht m>. Acesso em: 02 Out. 2016 